Supplementary information for

\title{
Simulating Marine Isotope Stage 7 with a coupled climate-ice sheet model
}

5 Dipayan Choudhury ${ }^{1,2}$, Axel Timmermann ${ }^{1,2}$, Fabian Schloesser ${ }^{3}$, Malte Heinemann ${ }^{4}$ and David Pollard ${ }^{5}$

${ }^{1}$ Center for Climate Physics, Institute for Basic Science (IBS), Busan 46241, South Korea

${ }^{2}$ Pusan National University, Busan 46241, South Korea

${ }^{3}$ International Pacific Research Center, University of Hawaii at Manoa, Honolulu, HI 96822, USA

${ }^{4}$ Institute of Geosciences, Kiel University, 24118, Kiel, Germany

$10{ }^{5}$ Earth and Environmental Systems Institute, Pennsylvania State University, Pennsylvania 16802, USA

Correspondence to: Dipayan Choudhury (dipayanc@pusan.ac.kr)

15 This PDF file contains supplementary figures, Fig. S1 to Fig. S6 

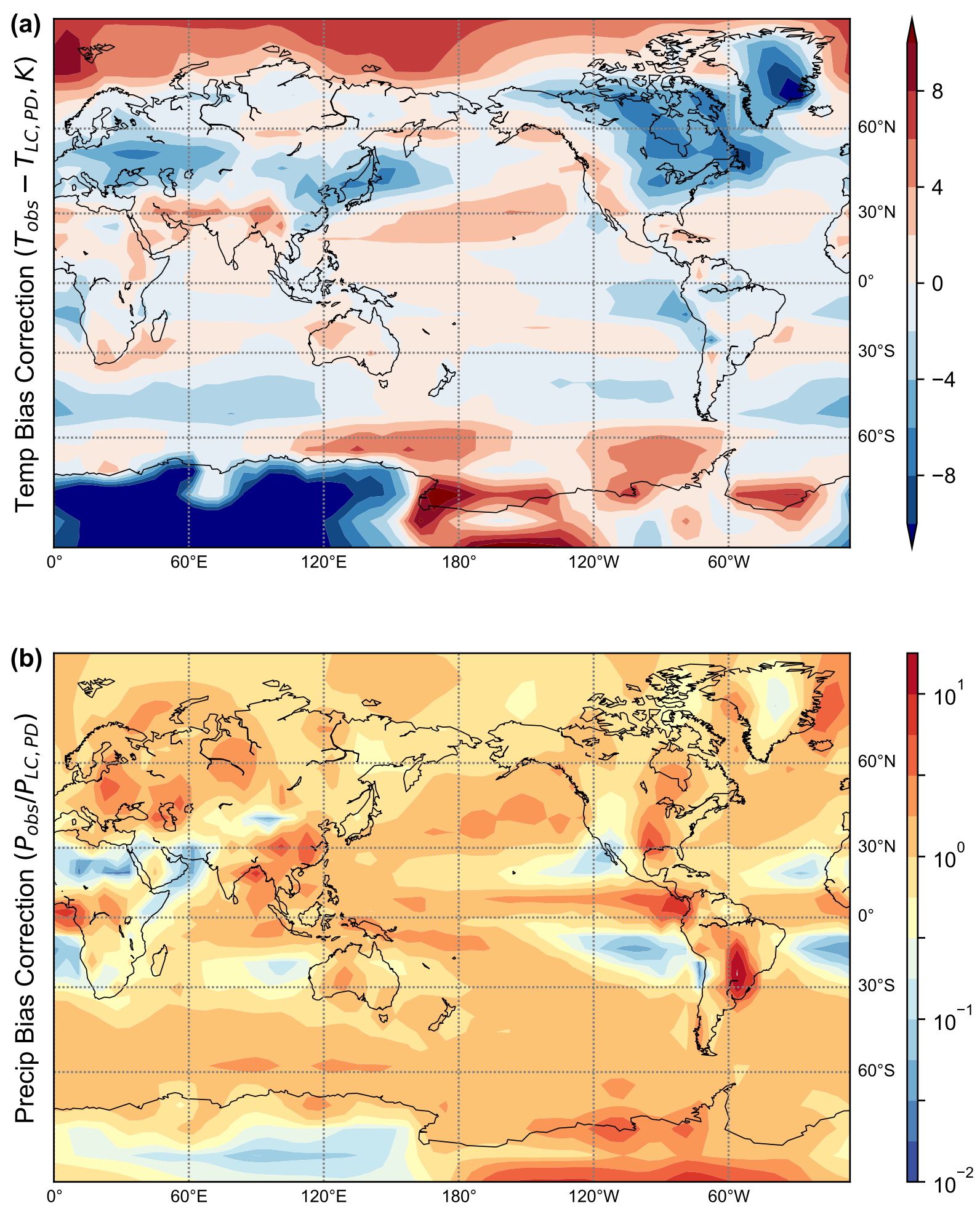

Figure S1: Bias correction used for LOVECLIM outputs. (a) Additive bias correction for annual mean surface temperature (K). (b) Multiplicative bias correction for annual mean precipitation. Colours are log normalised for the precipitation case. 

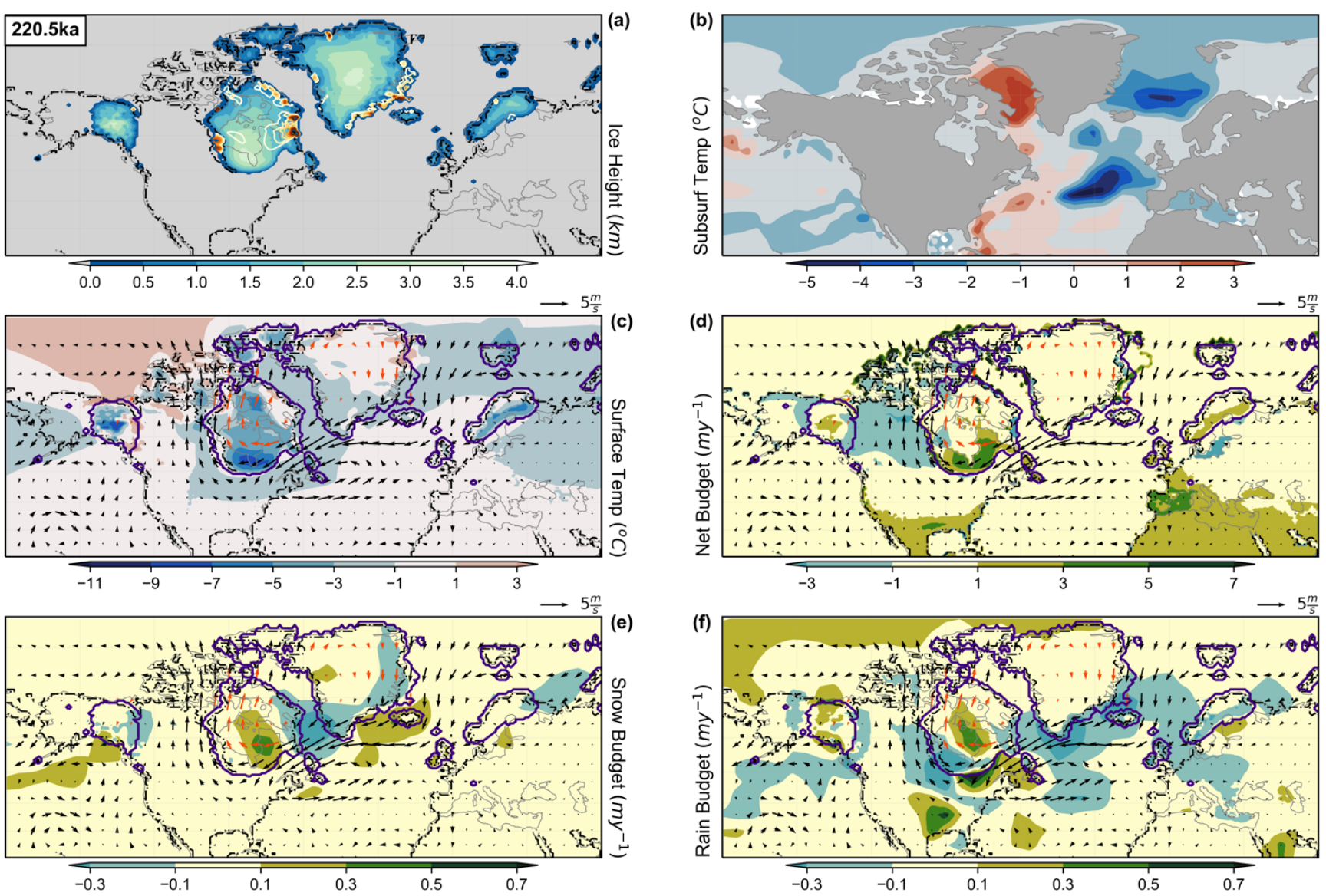

Figure S2: Simulated climate anomalies at 220.5ka over the Laurentide region. Anomalies here are with respect to the initial condition at 240ka. (a) Simulated anomalies in ice thickness (solid colors, $\mathrm{km}$ ); basal ice velocity (contours, my ${ }^{-1}$, contour levels same as in Fig. 4) and the grounding line (thick black lines). (b) Subsurface ocean temperature anomalies $\left({ }^{\circ} \mathrm{C}\right)$ at $400 \mathrm{~m}$ depth. (c) Surface temperature anomalies $\left({ }^{\circ} \mathrm{C}\right)$ overlaid with anomalous wind vectors at $800 \mathrm{hPa}\left(\mathrm{ms}^{-1}\right)$. The winds over regions with ice thickness greater than one $\mathrm{km}$ are plotted in red. (d) Net mass balance anomalies $\left(\mathrm{my}^{-1}\right)$ overlaid with anomalous winds $\left(\mathrm{ms}^{-1}\right)$. (e) Snowfall anomalies $\left(\mathrm{my}^{-1}\right)$ overlaid with absolute winds $\left(\mathrm{ms}^{-1}\right)$. (f) Rainfall anomalies $\left(\mathrm{my}^{-1}\right)$ overlaid with anomalous winds $\left(\mathrm{ms}^{-1}\right)$. The purple line in (c) to (f) mark the boundaries of the ice sheets and ice shelves. Anomalies over the Eurasian ice sheet are small and not shown. 

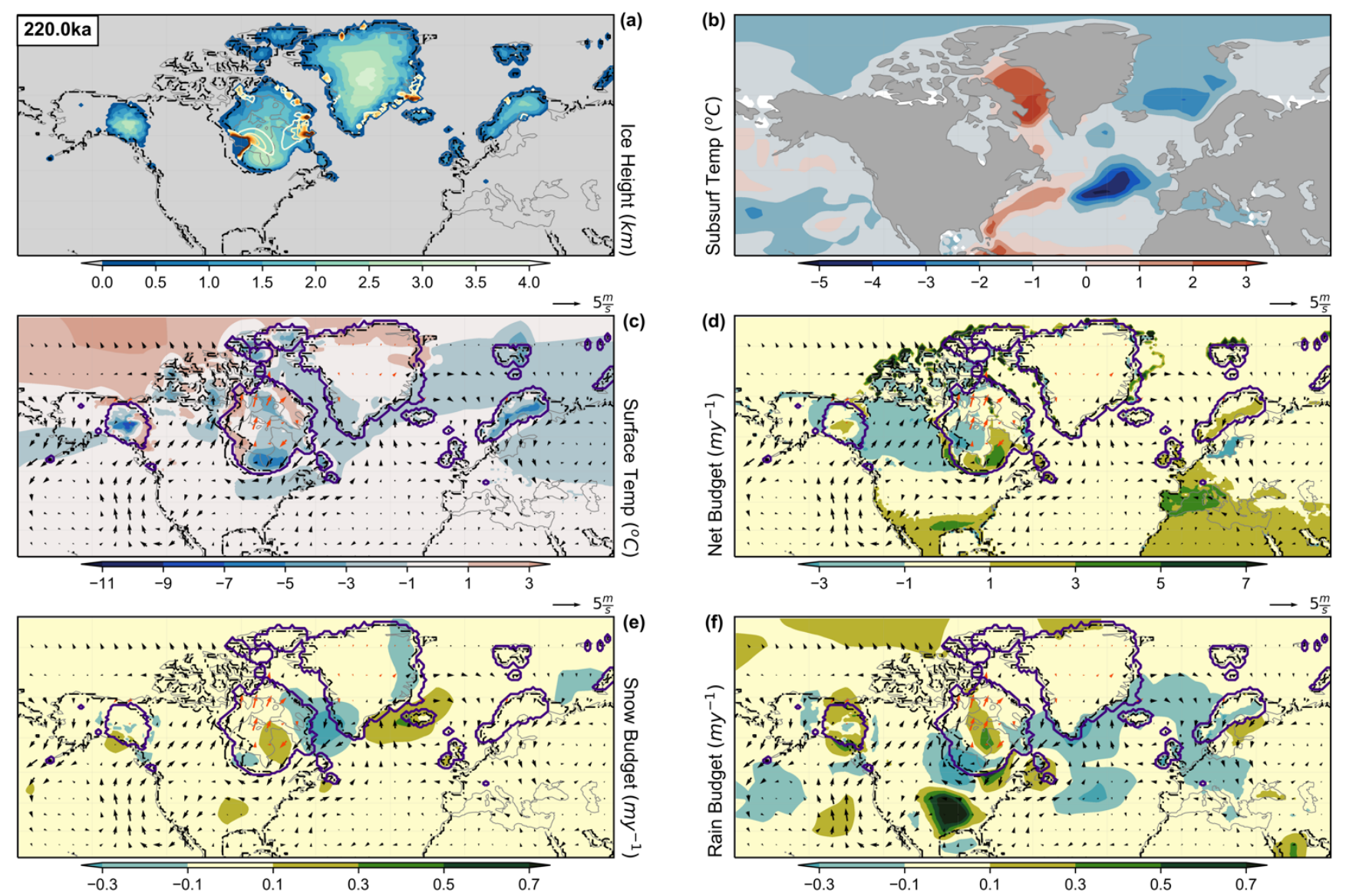

Figure S3: Simulated climate anomalies at 220.0ka over Laurentide. Anomalies here are with respect to the initial condition at 240ka. (a) Simulated anomalies in ice thickness (solid colors, $\mathrm{km}$ ); basal ice velocity (contours, $\mathrm{my}^{-1}$, contour levels same as in Fig. 4) and the grounding line (thick black lines). (b) Subsurface ocean temperature anomalies $\left({ }^{\circ} \mathrm{C}\right.$ ) at $400 \mathrm{~m}$ depth. (c) Surface temperature anomalies $\left({ }^{\circ} \mathrm{C}\right)$ overlaid with anomalous wind vectors at $800 \mathrm{hPa}\left(\mathrm{ms}^{-1}\right)$. The winds over regions with ice thickness greater than one $\mathrm{km}$ are plotted in red. (d) Net mass balance anomalies $\left(\mathrm{my}^{-1}\right)$ overlaid with anomalous winds ( $\left.\mathrm{ms}^{-1}\right)$. (e) Snowfall anomalies $\left(\mathrm{my}^{-1}\right)$ overlaid with absolute winds $\left(\mathrm{ms}^{-1}\right)$. (f) Rainfall anomalies $\left(\mathrm{my}^{-1}\right)$ overlaid with anomalous winds $\left(\mathrm{ms}^{-1}\right)$. The purple line in (c) to (f) mark the boundaries of the ice sheets and ice shelves. Anomalies over the Eurasian and Siberian ice sheets are small and not shown. 

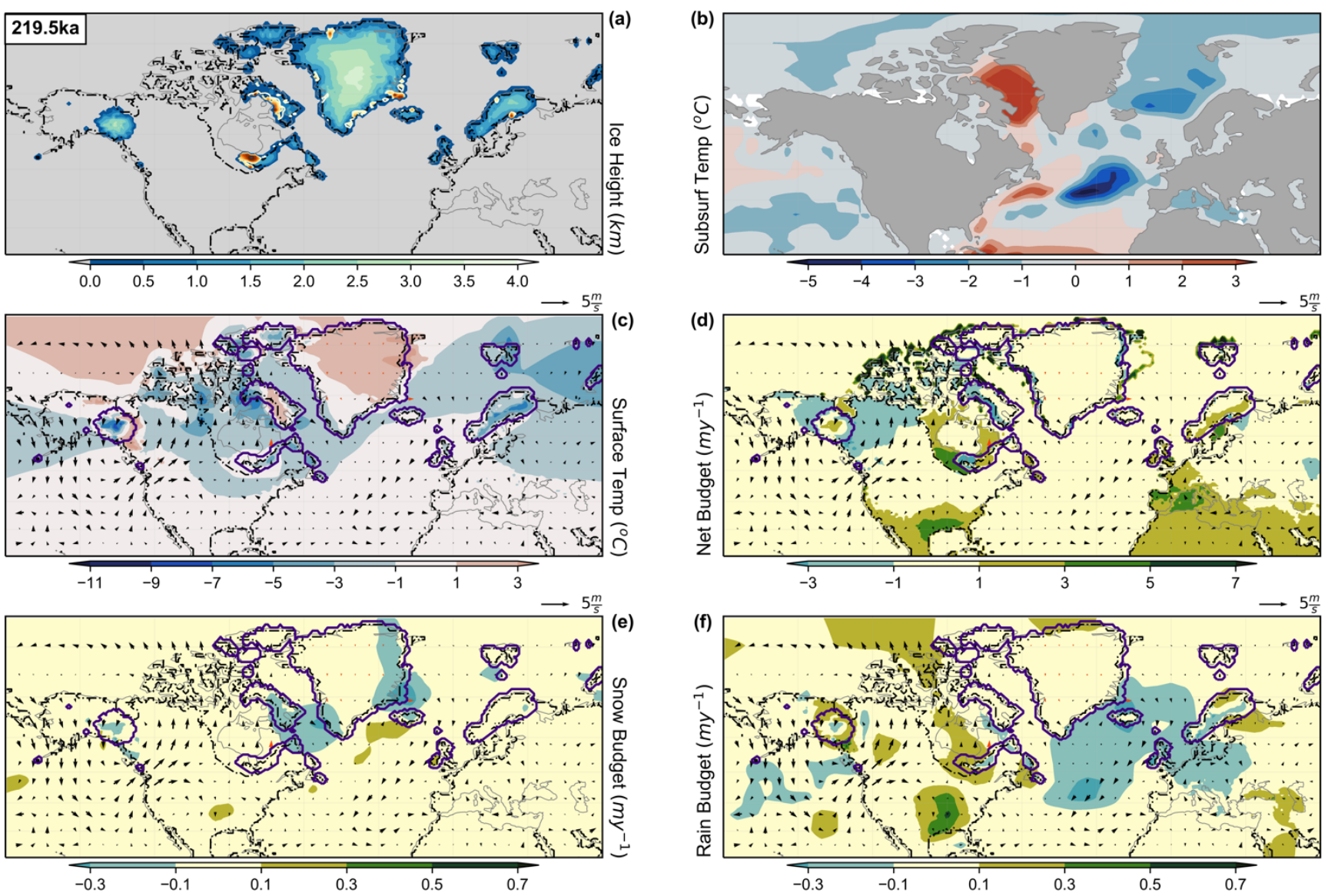

Figure S4: Simulated climate anomalies at $219.5 \mathrm{ka}$ over Laurentide. Anomalies here are with respect to the initial condition at 240ka. (a) Simulated anomalies in ice thickness (solid colors, $\mathrm{km}$ ); basal ice velocity (contours, $\mathrm{my}^{-1}$, contour levels same as in Fig. 4) and the grounding line (thick black lines). (b) Subsurface ocean temperature anomalies $\left({ }^{\circ} \mathrm{C}\right.$ ) at $400 \mathrm{~m}$ depth. (c) Surface temperature anomalies $\left({ }^{\circ} \mathrm{C}\right)$ overlaid with anomalous wind vectors at $800 \mathrm{hPa}\left(\mathrm{ms}^{-1}\right)$. The winds over regions with ice thickness greater than one $\mathbf{~ k m}$ are plotted in red. (d) Net mass balance anomalies $\left(\mathrm{my}^{-1}\right)$ overlaid with anomalous winds $\left(\mathrm{ms}^{-1}\right)$. (e) Snowfall anomalies $\left(\mathrm{my}^{-1}\right)$ overlaid with absolute winds $\left(\mathrm{ms}^{-1}\right)$. (f) Rainfall anomalies $\left(\mathrm{my}^{-1}\right)$ overlaid with anomalous winds $\left(\mathrm{ms}^{-1}\right)$. The purple line in (c) to (f) mark the boundaries of the ice sheets and ice shelves. Anomalies over the Eurasian and Siberian ice sheets are small and not shown. 

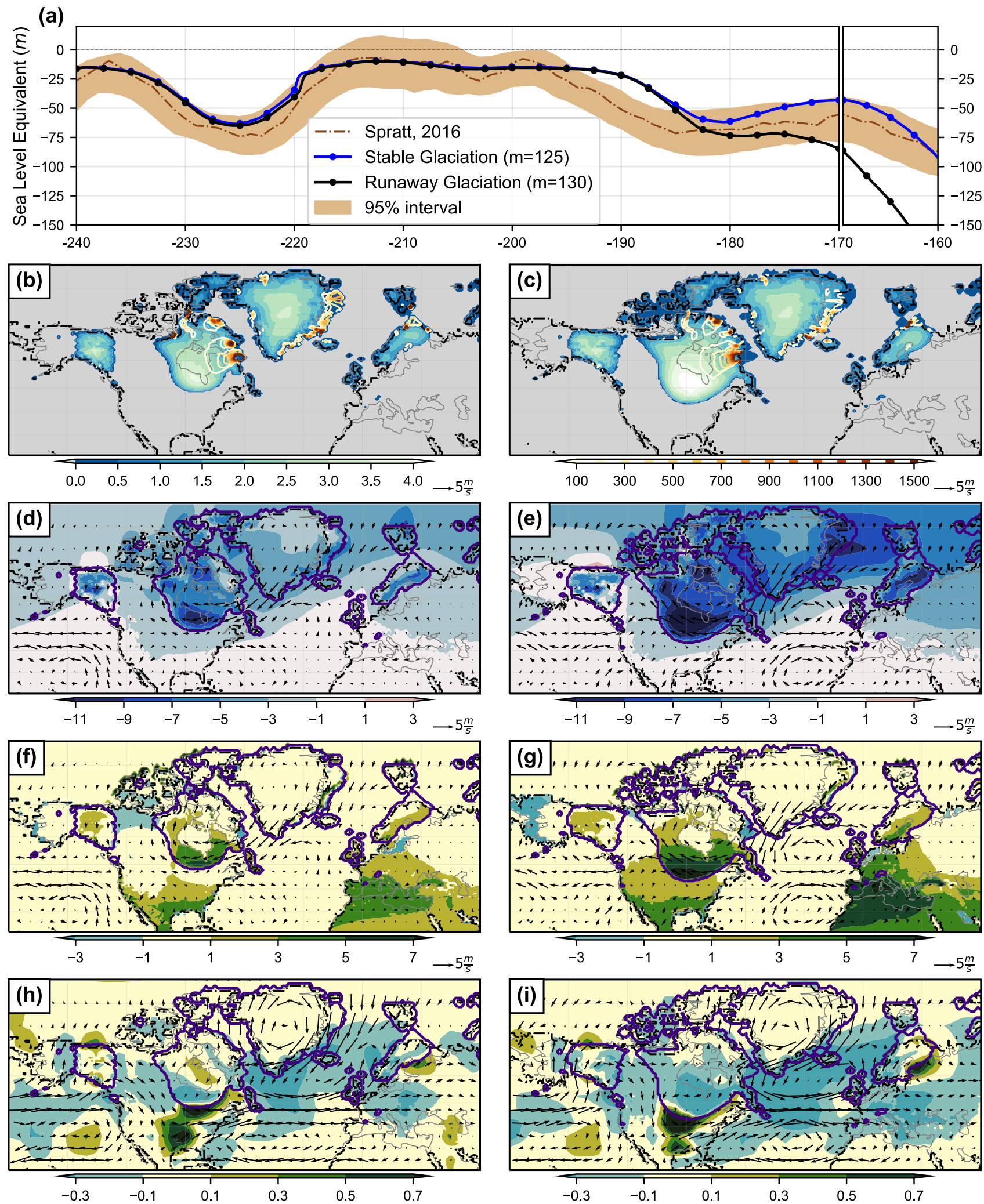

Figure S5: Bifurcation of the system at 170ka while transitioning into MIS 6 over Laurentide. (a) Sea level reconstruction (m) and 95\% confidence interval of Spratt and Lisiecki (2016) (brown). Total ice volume (in terms of SLE, m) from two ensembles of LOVECLIP, one that leads to a stable glacial inception (blue; $\alpha=2, m=125 \mathrm{Wm}^{-2}$ ) and another into a runaway glaciation (black; $\left.\alpha=2, m=130 \mathrm{Wm}^{-2}\right)$. Climate and ice sheet variables at 170ka from the stable glaciation on the left column (b, $d, f$ and $\left.h\right)$ and runaway glaciation on the right (c, e, g and i). (b,c) Ice thickness (solid colors, $\mathbf{k m}$ ) overlaid with basal ice velocity (colored contours, $\mathrm{my}^{-1}$ ) and the grounding line (black dotted lines). (d,e) Surface temperature anomalies $\left({ }^{\circ} \mathrm{C}\right)$ overlaid with anomalous wind vectors at $800 \mathrm{hPa}\left(\mathrm{ms}^{-1}\right)$. (f,g) Net mass balance anomalies $\left(\mathrm{my}^{-1}\right)$ overlaid with anomalous winds $\left(\mathrm{ms}^{-1}\right)$. (h,i) Rainfall anomalies $\left(\mathrm{my}^{-1}\right)$ overlaid with absolute winds $\left(\mathrm{ms}^{-1}\right)$. The purple contours in (d) to (i) mark the boundaries of the ice sheets. Anomalies here are with respect to the initial condition at 240ka. Anomalies over the Eurasian and Siberian ice sheets are small and not shown. 

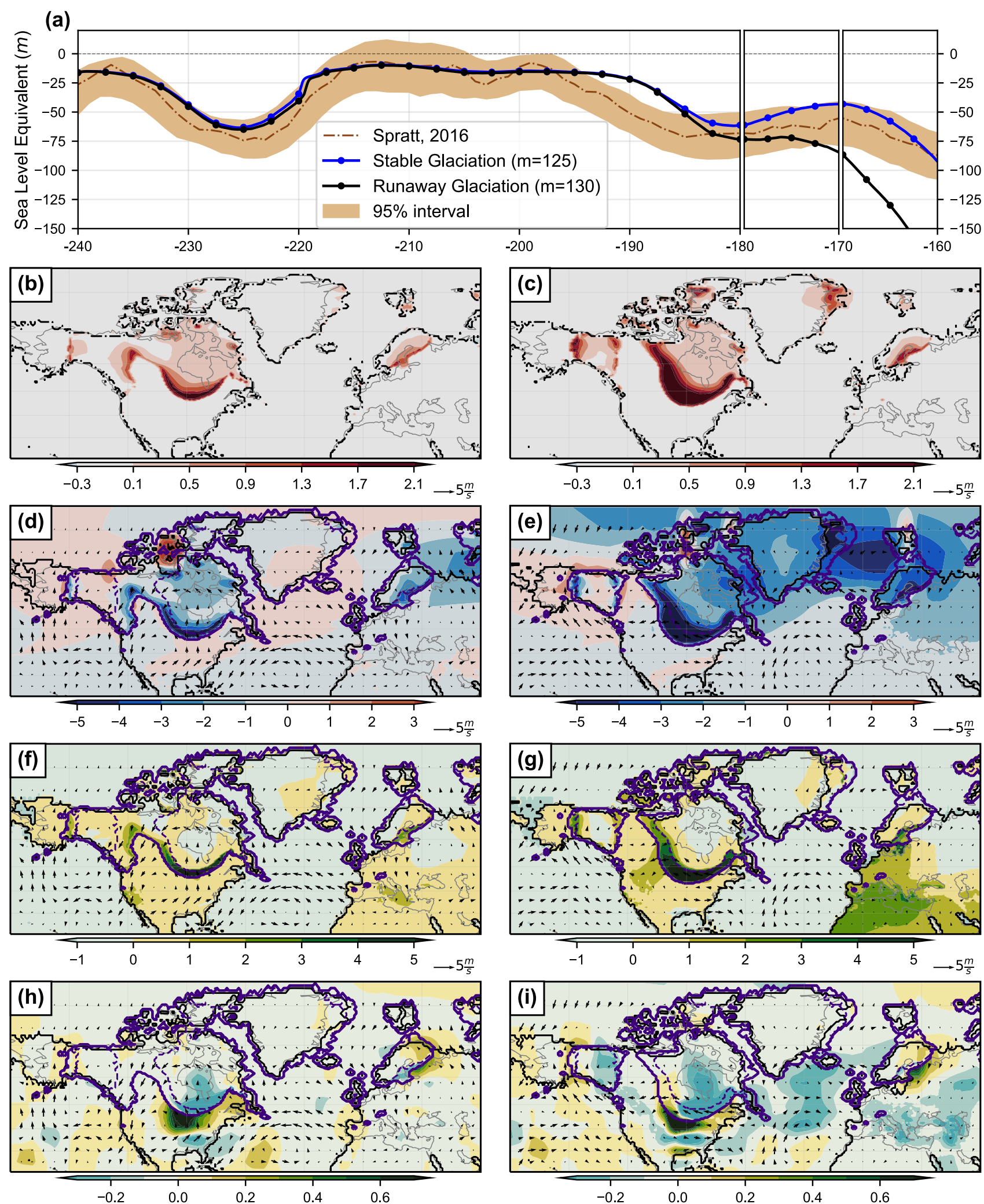

Figure S6: Difference between the simulations at the 180ka and 170ka over Laurentide. (a) Sea level reconstruction (m) and 95\% confidence interval of Spratt and Lisiecki (2016) (brown). Total ice volume (in terms of SLE, $m$ ) from two ensembles of LOVECLIP, one that leads to a stable glacial inception (blue; $\alpha=2, m=125 \mathrm{Wm}^{-2}$ ) and another into a runaway glaciation (black; $\alpha=2, m=130$ $\mathrm{Wm}^{-2}$ ). Difference in values between the runaway ensemble and the stable ensemble at 180ka (left column) and 170ka (right column) for $(b, c)$ Ice thickness (solid colors, $\mathrm{km})$; (d,e) surface temperature $\left({ }^{\circ} \mathrm{C}\right.$ ) and winds at $800 \mathrm{hPa}$ (vectors, $\left.\mathrm{ms}^{-1}\right)$; (f,g) net mass balance $\left(\mathrm{my}^{-1}\right)$ winds at $800 \mathrm{hPa}\left(\right.$ vectors, $\left.\mathrm{ms}^{-1}\right)$; and $(\mathrm{h}, \mathrm{i})$ rainfall $\left(\mathrm{my}^{-1}\right)$ winds at $800 \mathrm{hPa}$ (vectors, $\left.\mathrm{ms}^{-1}\right)$. The solid and dashed purple lines in (d) to (i) mark the boundaries of the ice sheets from the runaway ensemble and the stable ensemble respectively. Anomalies over the

70 Eurasian and Siberian ice sheets are small and not shown. 


\section{References:}

Spratt, R. M., and Lisiecki, L. E.: A Late Pleistocene sea level stack, Climate of the Past, 12, 1079-1092, 2016. 